\section{Performance in extinction as a function of deprivation and incentive in training*}

\author{
MELVIN H. MARX \\ University of Missouri, Columbia, Mo. 65201
}

The experiment was designed to determine the relationship between food deprivation and food incentive when the former variable is manipulated by ad lib feeding vs a single $(10-\mathrm{g})$ meal daily and the latter variable by concentration of sucrose. Rats highly deprived and highly rewarded remained relatively resistant to extinction, as did rats not deprived but given the low reward, whereas deprived rats given the low reward extinguished rapidly. It is concluded that the presumed deleterious influence of frustration on nonreinforced performance may not occur under the conditions of deprivation and incentive used in the present experiment.

Several recent experiments in this laboratory have produced results suggesting that the food-deprivation variable interacts with the incentive variable in the determination of resistance to extinction. For example, in one series of experiments (Dunham \& Marx, 1967; Dunham, 1967; Marx, 1968), markedly reduced resistance to extinction has been consistently found in high-drive Ss which suffered a radical reduction in quality and quantity of incentive from magazine to barpress trials given in daily paired sessions for 1 week prior to test. This result was identified as a frustration-suppression effect (FSE) on the assumption that a more significant amount of frustration would occur in the high-deprived Ss than in the nondeprived $\mathrm{Ss}$ as a consequence of the severe reduction in incentive associated with acquisition of the barpress response. The high-deprived downshifted Ss typically train as well as their nonshifted controls, but their performance breaks down rapidly in extinction from the high level of their terminal training (and of the first few extinction trials).

Another recent experiment (Marx, 1967) demonstrated that Ss trained under high-deprivation conditions and given a larger incentive extinguish reliably faster than Ss trained under low-deprivation conditions and given the same larger incentive, with small-incentive groups occupying an intermediate position. This result, which confirmed that of an earlier experiment (Reynolds, Marx, \& Henderson, 1952), was interpreted as supporting the view that frustration $h$ as a deleterious effect on nonreinforced performance.

The purpose of the present

*This research was supported in part by Grants GB-5853 and GB-8506 from the $N$ ational Science Foundation and by Research Career Award 1-K-6-MH22023 from the National Institute of Mental Health. experiment was to relate performance in extinction to food deprivation and incentive conditions where the incentive manipulation was in terms of percentage of sucrose concentration in water rather than amount of food.

SUBJECTS AND APPARATUS

The $S$ s were 32 female hooded rats (Long-Evans strain), 110 days old at the start of the experiment. Owing to death, ill health, and $E$ error, 8 of these were lost so that a total of $24 \mathrm{Ss}$ completed the experiment and provided the data. The apparatus was a set of eight controlled-operant conditioning boxes with retractable bars (previously described in detail in Marx et al, 1965).

EXPERIMENTAL DESIGN

The design was a simple 2 by 2 factorial. Half of the Ss were run throughout the experiment on an ad lib feeding schedule (labeled ND, for nondeprived), and the other half were fed $10 \mathrm{~g}$ of Purina meal once a day at the conclusion of the experimental session (labeled $D$, for deprived). Half of each of these two groups were given $8 \%$ sucrose in water as an incentive and the other half, $64 \%$ sucrose in water. The four groups were thus D-8, D-64, ND-8, and ND-64. In some analyses, "days" was added to the above design as a repeated measures factor with three levels (extinction days).

\section{PROCEDURE}

Magazine Training

Following 1 day of priming with a few drops of the appropriate sucrose concentration placed in a glass cup in the home cage of each rat, 3 days of magazine training were given with 12 trials daily, $.1 \mathrm{ml}$ of $8 \%$ or $64 \%$ sucrose being delivered per trial on a $60-\mathrm{sec}$ schedule.

\section{Barpress Training}

Ten days of barpress training were given, with 12 trials daily on a CI 60/60 schedule; the bar was presented for a controlled interval of 60 sec, retracting at press or automatically if not pressed within $60 \mathrm{sec}$, and each such retraction, marking a trial, was followed by a $60 \mathrm{sec}$ intertrial interval.

Extinction

Three test days were administered, with $20 \mathrm{CS} 30 / 30$ trials on each. The controlled session program consisted of continuous presentation of the bar for the time indicated, permitting a period of free operant responding. In the present case, this time was 30 sec, with a 30-sec intertrial interval, and each barpress produced an empty magazine cup.

\section{RESULTS}

The mean number of barpresses for each group is plotted for the 3 test days in Fig. 1, designed to show the interactions between deprivation and incentive variable. Group D-8 performed at an inferior rate throughout the 3 test days. Group ND-64 was also inferior on Day 1, while Group D-64 was slightly superior. An analysis of variance performed on these data indicated that neither main effect was reliable (deprivation $\mathrm{F}<1.00$, incentive concentration $F=2.50, p>.05$ for $1,20 \mathrm{df}$; unless otherwise noted, all Fs given below are for 1,20 df). However, the interaction of Deprivation by Incentive Concentration was reliable $(F=7.72, \quad p<.05)$. Moreover, the triple interaction of Deprivation by Incentive Concentration by Days was also reliable $(F=6.52, p<.01$ for $2,40 \mathrm{df}$ ), confirming the suggestion of a diminution in the main effects interaction suggested by the curves shown in Fig. 1

It is quite apparent that under conditions of deprivation there was a consistent increment in performance from $8 \%$ to $64 \%$ concentration and

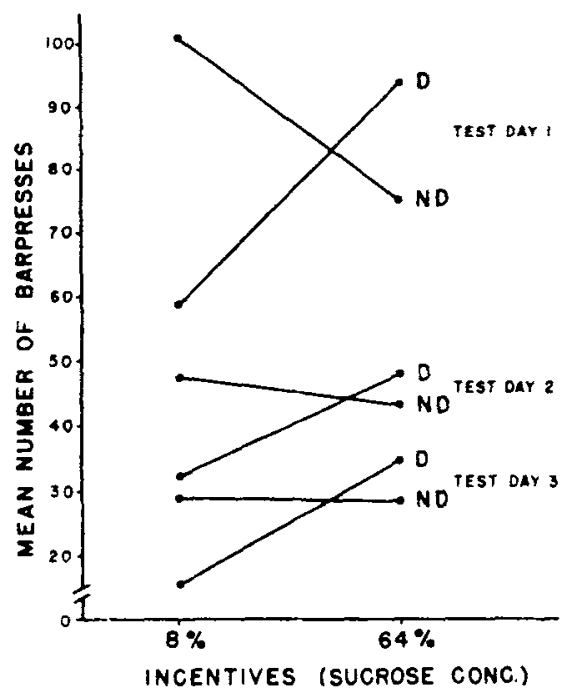

Fig. 1. Mean number of barpresses over 3 test extinction days. 


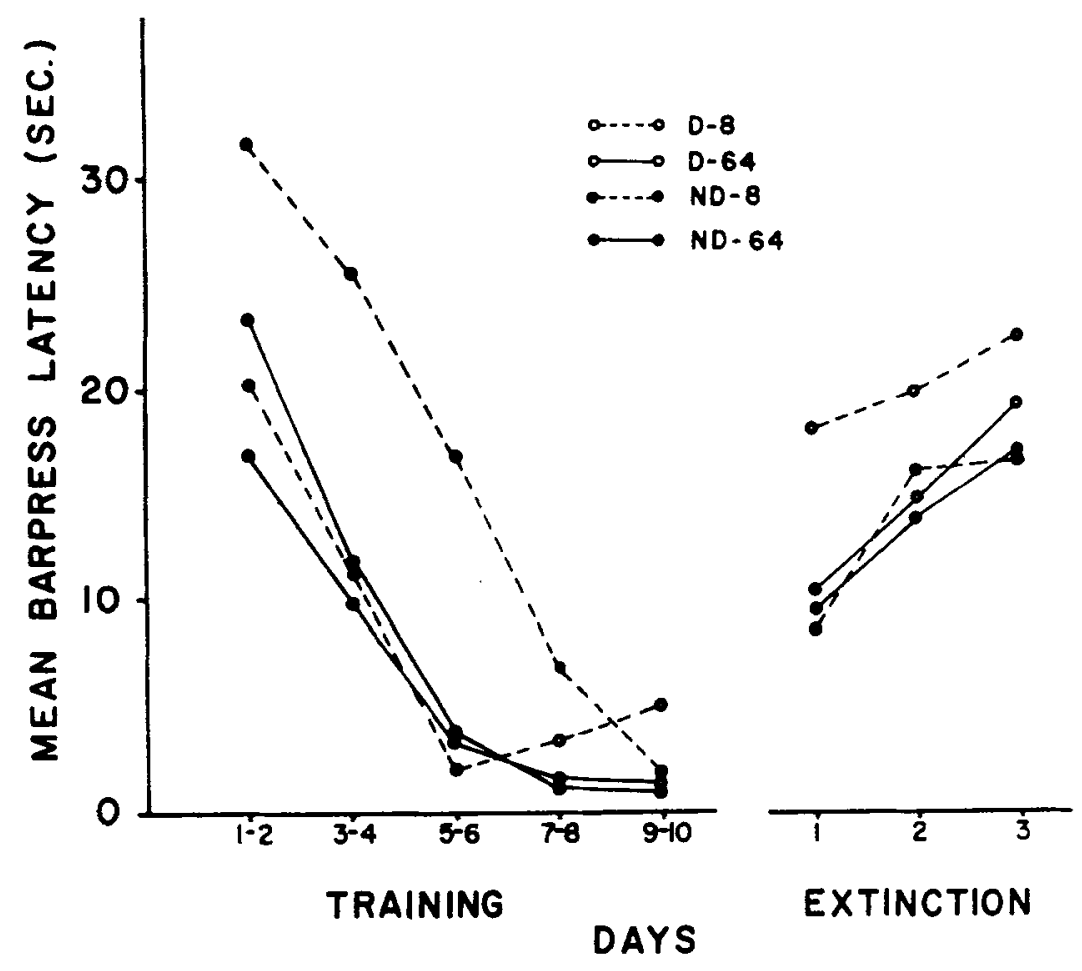

Fig. 2. Mean barpress latencies in training and extinction.

that this relationship showed only a very slight change over the last 2 test days. An opposite relationship for the nondeprived animals clearly occurred on the first test day, with $64 \%$ training incentives producing fewer rather than more responses, but did not hold up over the last 2 test days.

A separate analysis of variance was performed on the data of Day 1 . Neither main effect was reliable, but their interaction was $(F=12.67$, p $<.01)$. The triple interaction with days was not reliable $(F=1.20)$, although the interaction of Incentive Concentration by Blocks of 4 Trials was reliable $(F=6.32, p<.01$ for $4,60 \mathrm{df}$ ).

Measures of response latency for the first barpress on each 30 -sec test trial were also taken. These are plotted in Fig. 2, along with the mean latency scores for the training trials, with training trials paired for simplicity of presentation. Here an early training inferiority of Group ND-8 seems to have occurred, although neither main effect was reliable (deprivation $F=1.94, \quad p>.05 ;$ incentive concentration $\mathrm{F}=2.08, \mathrm{p}>.05$ ), nor was there any interaction between them $(F<1.00)$.

Analysis of variance of these extinction scores, in which Group D-8 was again markedly inferior, revealed a number of reliable differences in latency. On Day 1, for example, the

$(\mathrm{F}=5.47, \mathrm{p}<05)$ On Day 2 as the plotted points suggest, only the incentive concentration effect was On Day 3 , again as suggested by the effect was reliable $(F=6.20, p<.05)$, the faster responding. The shift in improvement of Group ND-8.

$$
\text { DISCUSSION }
$$
deprivation and sucrose concentration interact in the determination of deprivation variable apparently maximizes the effect of the incentive concentration in training producing superior and the lower concentration inferior test performance. These results are in accord with the incentives may be presumed to have on response strength. Under nondeprivation conditions, on the
Day 1, which may be tentatively attributed to the slightly aversive effect sometimes evidenced by very high concentrations of sucrose.

The various interactions found in the present study are clearly quite different from those found in the previous experiment (Marx, 1967), in which number of food pellets rather than concentration of sucrose was varied and a different deprivation procedure was used. The present results suggest that the deleterious effects of a presumed aversive frustration state do not occur under the motivational-incentive conditions of this experiment.

The present results may also be compared with some previous data involving $8 \%$ and $64 \%$ sucrose incentives. In the present experiment, there was a retardation of performance (facilitation of extinction) in Ss which received relatively poor reward but under high-deprivation conditions (Group D-8). In the previous experiments (Marx, 1966), the Ss receiving $8 \%$ sucrose incentive in training were markedly inferior in extinction-but only if they had also received $64 \%$ incentives in early training. Thus, the same general result was achieved as in this experiment, but with a different manipulationreduction of the effective value of the $8 \%$ incentive by a contrast operation. Whether or not this similar result is mediated by a similar mechanism, presumably involving some kind of contrast effect, remains to be determined. reliable $(F=4.35, p=.05)$, with the $64 \%$ groups showing faster responding. plotted values, only the deprivation with the nondeprived groups showing results from Day 2 to Day 3 was obviously caused by the relative

These results demonstrate that food performance in extinction. The variable, with the higher sucrose motivational influences that the two other hand, a reversal of this relationship occurred, particularly on

\section{REFERENCES}

DUNHAM, $P$. J. Incentive contrast and deprivation factors in a discrete-trial bar-press situation. Journal of Comparative \& Physiological Psychology, 1967, 64, 485-487.

DUNHAM, P. J., \& MARX, M. H. The frustration-suppression effect in a discrete-trial operant situation. Journal of Comparative \& Physiological Psychology, $1967,63,45-49$.

MARX, M. H. The activation of habits. Psychological Reports, 1966, 19, 527-550.

MARX, M. $H$. Interaction of drive and reward as a determiner of resistance to extinction. Journal of Comparative \& Physiological Psychology, 1967, 64, 488-489.

MARX, M. H. The frustration-suppression effect: A replication with variation in amount of prior magazine training. Journal of Comparative \& Physiological Psychology, 1968, 66, 231-233.

MARX M. H. TOMBAUGH, T, N. HATCH, R. S., \& TOMBAUGH, J. W. Controlled operant conditioning boxes with discrete-trial programming for multiple experimental use. Perceptual \& Motor Skills, 1965, $21,247-254$.

REYNOLDS, B., MARX, M. H., \& HENDERSON, R. L. Resistance to extinction as a function of drive-reward interaction. Journal of Comparative \& Physiological Psychology, 1952, 45, 36-42. 